\title{
Brain region linked to post-terror stress
}

\section{David Cyranoski, Tokyo}

Researchers studying the long-term effects of the 1995 sarin gas attack in the Tokyo underground have unearthed some intriguing clues about what controls different people's susceptibility to the psychological after-effects of shock.

Hidenori Yamasue, a psychiatrist at the University of Tokyo, has been looking at images of the brains of survivors of the attack. He found that of 25 survivors studied, the volume of an area of the brain known as the anterior cingulate cortex (ACC) was smaller, on average, in the nine who were diagnosed with post-traumatic stress disorder. The degree of size reduction correlated with the severity of the symptoms.

The finding, reported this week in the Proceedings of the National Academy of Sciences $(100,9039-9043 ; 2003)$, could help to clarify a difficult area of neuroscience. Several previous studies searching for a link between the size of a different area of the brain, the hippocampal region, and stress symptoms have produced inconclusive results.

But Yamasue has found signs of a much stronger link between the size of the ACC and the occurrence of post-traumatic stress. Many of those hurt in the Tokyo attack have shown symptoms of the disorder, ranging from nightmares and flashbacks to fear of riding trains.

Yamasue used an innovative magnetic resonance imaging technique that divides the brain into about a million small elements for computer analysis, enabling him to look at the whole brain at once. The results showed no correlation between the stress

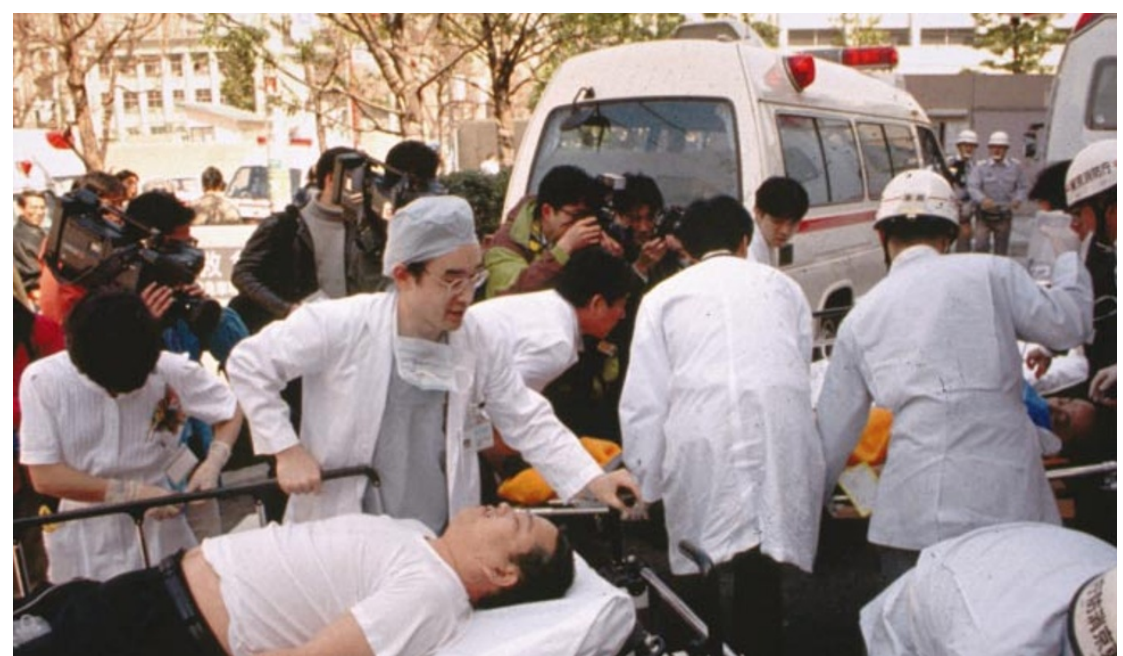

Many survivors of the 1995 sarin gas attack in Tokyo later suffered from post-traumatic stress.

symptoms and the size of the hippocampal region. "We looked over the whole brain and only the ACC region was different," he says.

A recent study of medical workers who served with the US army in Vietnam also suggested a correlation between the size of the ACC and post-traumatic stress (S. L. Rauch et al. NeuroReport 14, 913-916; 2003). But Roger Pitman, a Harvard psychiatrist and co-author of the study, believes that the size of the hippocampal region could correlate with post-traumatic stress in victims of "chronic, long-standing" trauma, including the subjects of most of the previous studies.

But researchers still don't know whether a smaller brain region is a result of the stress, or a pre-existing condition, perhaps genetic in origin, that made the subject more likely to display symptoms. Investigating possible links between hippocampal size and posttraumatic stress, Pitman has studied twins of whom one had experienced trauma (M. W. Gilbertson et al. Nature Neurosci. 5, 12421247; 2002). His results tentatively suggest that the size factor may be a pre-existing condition but "the jury is still out on this", he says.

Linking post-traumatic stress with specific areas of the brain could eventually aid the treatment of its victims. "If we understand the changes in brain structure and function we can develop better treatments targeted at specific brain pathways," says Gerardo Villarreal, a psychiatrist at the University of New Mexico.

\section{Museum trustees quit after row over sale of artefacts}

\section{Rex Dalton, San Diego}

The board of trustees at a leading museum in the western United States has resigned, following an outcry over the sale of some of its collection to help cover operating costs.

The Museum of Northern Arizona (MNA) in Flagstaff, best known for its archaeology and palaeontology collections, will hold a meeting of its supporters on 26 July to elect new trustees to try to end what local scientists describe as a year of financial and administrative turmoil at the museum.

On 11 July, the museum's trustees and its director, Robert Baughman, said they would resign with effect from 26 July, after leading donors and museum supporters set up a petition to force them out.

Baughman and the trustees declined to comment on the resignations, but a museum statement said that they were intended "to restore confidence in the institution".

Over 75 years, the museum has curated one of the nation's leading collections of Native American artefacts and art, together with dinosaur and geological specimens.

But along with many other US museums, the MNA has been going through tough financial times (see Nature 423, 575; 2003). Early last year, when it was running out of operating funds, the museum's leadership made the decision to declare some pieces of the art and archaeology collection 'non-performing assets' and sell them for about $\$ \mathbf{8 5 0 , 0 0 0}$ to a private dealer.

Among the items sold were half a dozen sandpainting textiles by Hosteen Klah, an esteemed ceremonial practitioner in the Navajo tribe who died in 1937. "This never should have happened," says Susan Brown McGreevy, an authority on Klah's work and former director of the Wheelwright Museum of the American Indian in Santa Fe, New Mexico. "It was an act of total irresponsibility."

When details of the sale became known earlier this year, a museum donor, Cynthia Perin, filed a complaint with the American Association of Museums (AAM). Perin says that the AAM has opened an investigation, as its ethics code forbids the sale of part of the collection to generate operating revenue. Perin says she is "appalled" by the museum's actions, including the scaling-back of its geology department.

AAM-accredited museums, such as the MNA, should not consider their collections as assets, says Ed Able, the AAM's president. Able declined to confirm that an investigation was under way, but says that he has never known a museum board to resign en masse. 